\title{
A lightweight carbon nanofiber-based 3D structured matrix with high nitrogen-doping level for lithium metal anodes
}

\author{
Haoliang $\mathrm{Wu}^{1}$, Yunbo Zhang ${ }^{2}$, Yaqian Deng ${ }^{3}$, Zhijia Huang ${ }^{2}$, Chen Zhang ${ }^{3}$, Yan-Bing $\mathrm{He}^{3}$, \\ Wei $\mathrm{Lv}^{3 *}$ and Quan-Hong Yang ${ }^{1 *}$
}

\begin{abstract}
Lithium metal is considered to be the most promising anode material for the next-generation rechargeable batteries. However, the uniform and dendrite-free deposition of $\mathrm{Li}$ metal anode is hard to achieve, hindering its practical applications. Herein, a lightweight, free-standing and nitrogen-doped carbon nanofiber-based $3 \mathrm{D}$ structured conductive matrix (NCNF), which is characterized by a robust and interconnected 3D network with high doping level of 9.5 at\%, is prepared by electrospinning as the current collector for $\mathrm{Li}$ metal anode. Uniform $\mathrm{Li}$ nucleation with reduced polarization and dendrite-free $\mathrm{Li}$ deposition are achieved because the NCNF with high nitrogen-doping level and high conductivity provide abundant and homogenous metallic $\mathrm{Li}$ nucleation and deposition sites. Excellent cycling stability with high coulombic efficiency are realized. The Li plated NCNF was paired with $\mathrm{LiFePO}_{4}$ to assemble the full battery, also showing high cyclic stability.
\end{abstract}

Keywords: lithium metal anode, nucleation, dendrite-free, nitrogen-doping, overpotential

\section{INTRODUCTION}

Lithium ion batteries (LIBs) are approaching the theoretical limit of cathode/anode materials and the demand for high energy density battery system is growing [1-6]. Lithium metal batteries (LMBs) are considered to be one of the most promising next-generation energy storage systems because of the highest capacity $\left(3,860 \mathrm{~mA} \mathrm{~h} \mathrm{~g}^{-1}\right)$ and the lowest potential $(-3.04 \mathrm{~V} v s$. the standard hydrogen electrode) of lithium metal [7-8]. Despite the high-energy-density of LMBs, the intractable Li dendrite growth and the resulted low coulombic efficiency, internal short circuit and even hazardous issues hinder the practical use of LMBs [9-12]. Tremendous efforts have been made to solve these problems. Various types of electrolyte additives, such as $\mathrm{Cs}^{+}$[13], FEC [14], polysulfide [15-16], $\mathrm{LiNO}_{3}$ [17-18], ionic liquid electrolytes [19] and $\mathrm{H}_{2} \mathrm{O}$ [20] have been used to form a stable and passivate layer on the Li metal anode. With adequately high shear modules to prevent the penetration of $\mathrm{Li}$ dendrites, solid electrolytes and gel polymer electrolytes have also been proposed to replace liquid electrolyte [2123]. Artificial SEI layer constructing before cell cycling was also proposed to protect the surface.[24-29] However, the volume changes of lithium metal during the cycling inevitably generate the stress which will destroy the above passivation layers. Thus, the conductive threedimensional (3D) framework structures for lithium deposition, like the porous $\mathrm{Cu}$ current collectors and threedimensional graphene framework, attract great attention because they can lower the local electrode current density and accommodate the large volume changes [30-36]. Several reviews have discussed the advantages of $3 \mathrm{D}$ structure for the Li metal anodes [37-38]. But the nonlithiophilic surfaces are not ideal for the uniform nucleation and deposition of lithium [39]. Thus, the surface modification is always needed [40].

Compared with the porous metals, the porous carbon

\footnotetext{
${ }^{1}$ Nanoyang Group, State Key Laboratory of Chemical Engineering, School of Chemical Engineering and Technology, Tianjin University, Tianjin 300072, China

${ }^{2}$ Tsinghua-Berkeley Shenzhen Institute (TBSI), Tsinghua University, Shenzhen 518055, China

${ }^{3}$ Engineering Laboratory for Functionalized Carbon Materials, Shenzhen Key Laboratory for Graphene-based Materials, Graduate School at Shenzhen, Tsinghua University, Shenzhen 518055, China

* Corresponding authors (emails: qhyangcn@tju.edu.cn (Yang QH); lv.wei@sz.tsinghua.edu.cn (Lv W))
} 
framework is lightweight which is benefit to improve the energy density based on the whole device. Moreover, the carbon surface is easy to be functionalized. Nitrogencontaining functional groups on carbon surface have been reported to interact with $\mathrm{Li}$ atoms and enhance the lithiophilicity, especially pyridinic nitrogen and pyrrolic nitrogen, which is promising to achieve a more uniform nucleation of metal $\mathrm{Li}$ with reduced polarization [41-42]. However, the nitrogen content in previous studies is relatively low and is insufficient for the uniform deposition of $\mathrm{Li}^{+}$ions on the porous framework with high surface area. As a result, a well-designed lightweight lithiophilic 3D carbon matrix is required to address the abovementioned issues of LMBs.

Herein, a lightweight and free-standing nitrogen-doped carbon nanofiber-based 3D structured conductive matrix (denoted NCNF) was used as the current collector to achieve the uniform $\mathrm{Li}^{+}$ion nucleation and deposition. The high nitrogen-doping content (9.5 at\%) provides enough active sites to guarantee the homogenous $\mathrm{Li} \mathrm{nu}$ cleation on the high surface area framework which reduces the nucleation overpotential and regulates the following Li growth. The mass density of NCNF is only $0.57 \mathrm{mg} \mathrm{cm}^{-2}$, much lighter than the commercial $\mathrm{Cu}$ current collector $\left(7.96 \mathrm{mg} \mathrm{cm}^{-2}\right)$. When the lithium loading is $4 \mathrm{~mA} \mathrm{~h} \mathrm{~cm}{ }^{-2}$, the mass density of Li@NCNF electrode is $1.61 \mathrm{mg} \mathrm{cm}^{-2}$, and that of Li@Cu electrode is $9.00 \mathrm{mg} \mathrm{cm}^{-2}$, showing its advantage on improving the energy density based on the whole cell. Such a lightweight 3D framework also lowers the local current density and accommodates the volume changes during cycling. As schematically illustrated in Fig. 1, the nucleation sites for $\mathrm{Cu}$ foil are limited because of the heterogeneous nonlithiophilic surface and the low surface area. Then the follow-up plating Li tends to deposit onto the existing $\mathrm{Li}$ nuclei, causing the uncontrollable Li dendrite growth. A low nitrogen-doped carbon framework cannot provide sufficient active sites for Li nucleation and deposition, causing uneven metal Li distribution. While, because of the high nitrogen-doping level of NCNF, the homogenous metallic $\mathrm{Li}$ nucleation and deposition was achieved throughout the NCNF matrix, suppressing the Li dendrite growth. Therefore, excellent cycling stability with a high coulombic efficiency over $98 \%$ for more than 250 cycles was obtained in the case of $1.0 \mathrm{~mA} \mathrm{~h} \mathrm{~cm}^{-2}$ at $1.0 \mathrm{~mA} \mathrm{~cm}^{-2}$ and over $97 \%$ for more than 120 cycles for $2.0 \mathrm{~mA} \mathrm{~h} \mathrm{~cm}^{-2}$ at $2.0 \mathrm{~mA} \mathrm{~cm}{ }^{-2}$. Moreover, when paired the $\mathrm{Li}$ plated NCNF and $\mathrm{LiFePO}_{4}$ to assemble a full cell, the reduced voltage polarization and high capacity retention of $82.4 \%$ after 300 cycles were achieved.

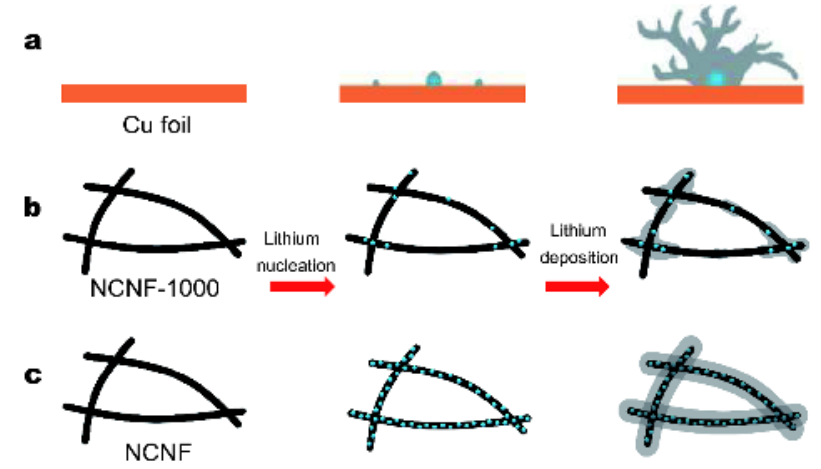

Figure 1 Schematic of the metallic Li nucleation and plating on $\mathrm{Cu}$ foil (a), NCNF-1000 (b) and NCNF (c).

\section{EXPERIMENTAL SECTION}

Polyaniline (PAN)-based film was prepared by electrospinning with the following details. $0.8 \mathrm{~g}$ PAN was dispersed in $10 \mathrm{~g} \quad \mathrm{~N}, \mathrm{~N}$-Dimethylformamide (DMF) via stirring at $60^{\circ} \mathrm{C}$ for $24 \mathrm{~h}$ to form a homogeneously solution. Then the well dispersed solution was loaded into an injection syringe $(10 \mathrm{~mL})$ with a stainless-steel hollowbore spray needle, which was connected to a high-voltage power supply. The high voltage was set at $18 \mathrm{kV}$ and the temperature was kept at $40^{\circ} \mathrm{C}$. The distance between electrodes was fixed at $15 \mathrm{~cm}$. Feeding rate of $1 \mathrm{~mL} \mathrm{~h}^{-1}$, collector spinning rate of $30 \mathrm{rpm}$ and cross travel of $50 \mathrm{~mm}$ were used for electrospinning. The electrospun PAN was collected and dried at $70^{\circ} \mathrm{C}$ in vacuum oven for $12 \mathrm{~h}$ to remove the DMF solvent. Then the electrospun films were heated to $270^{\circ} \mathrm{C}$ in air for $1 \mathrm{~h}$ with the heating rate of $5^{\circ} \mathrm{C} \mathrm{min}^{-1}$. Afterwards, the films were carbonized under the protection of $\mathrm{N}_{2}$ gas through a one-step heating process at 800 or $1,000^{\circ} \mathrm{C}$ for $2 \mathrm{~h}$ and the obtained samples were denoted as NCNF and NCNF-1000, respectively.

The microstructures of the samples were characterized by field emission scanning electron microscopy (FE-SEM, HITACHSU8010). Raman spectrum was recorded with a Lab RAM HR800 (Horiba) using $532 \mathrm{~nm}$ incident radiation. The electrical conductivity was obtained using a four-point probe (MCP-T610) method. Nitrogen adsorption-desorption was performed using an ASAP 2020 instrument (Micromeritics Instruments) at $77 \mathrm{~K}$. The specific surface area (SSA) was calculated using the Brunauer-Emmett-Teller (BET) method. X-ray photoelectron spectra (XPS) measurement was performed on an ESCALAB 250Xi (Thermo Fisher) with a monochromatic Al $\mathrm{Ka}$ source to analyze the surface species and their chemical states. 

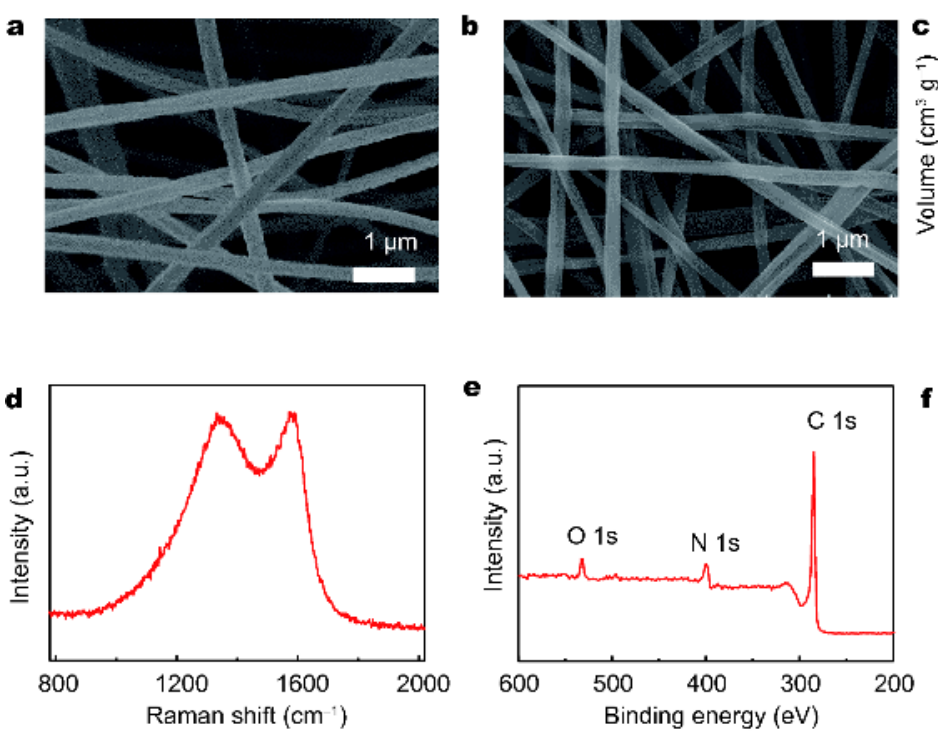

Figure 2 SEM images of the PAN-based film (a) and NCNF (b). Nitrogen adsorption/desorption isotherm (c). Raman spectra of NCNF (d). XPS survey spectrum of NCNF (e) and deconvoluted spectra of N 1s (f).

The electrochemical measurements were carried out with type 2032 coin cells by directly using the freestanding NCNF film as the working electrode, which was pouched into electrode disk with the diameter of $12 \mathrm{~mm}$ and area of $1.131 \mathrm{~cm}^{2}$. A lithium metal foil of $5 \mathrm{~mm}$ thick was used as the counter electrode. Commercial separator (Celgard 2400) was selected as the separator, which was cut into disk with a diameter of $20 \mathrm{~mm}$. The electrolyte applied in this experiment was $1 \mathrm{~mol} \mathrm{~L}^{-1}$ lithium bis(trifluoromethanesulfonyl)imide (LiTFSI) dissolved in 1,3dioxolane/1,2-dimethoxyethane (DOL/DME, 1:1 by volume) with $3 \mathrm{wt} \% \mathrm{LiNO}_{3}$ (Alfa Aesar) additive. Electrochemical impedance spectroscopy (EIS) was carried out using VMP3 electrochemical workstation (Bio Logic Science Instruments), with a frequency range of $100 \mathrm{kHz}$ to $10 \mathrm{MHz}$ and disturbance amplitude of $5 \mathrm{mV}$. The lithium metal plating/stripping test was performed using a Land $2001 \mathrm{~A}$ cell test system (Wuhan, China) at $25^{\circ} \mathrm{C}$. The current densities applied were 1.0 and $2.0 \mathrm{~mA} \mathrm{~cm}^{-2}$, and the specific capacities were 1.0 and $2.0 \mathrm{~mA} \mathrm{~h} \mathrm{~cm}^{-2}$ respectively. To be more specific, $1.0 \mathrm{~mA} \mathrm{~h} \mathrm{~cm}^{-2}$ $\left(2.0 \mathrm{~mA} \mathrm{~h} \mathrm{~cm}^{-2}\right)$ of Li was first plated onto the NCNF electrode at $1.0 \mathrm{~mA} \mathrm{~cm}{ }^{-2}\left(2.0 \mathrm{~mA} \mathrm{~cm}^{-2}\right)$, followed by $\mathrm{Li}$ stripping up to $1 \mathrm{~V}$ at the same current density. A higher areal capacity of $4 \mathrm{~mA} \mathrm{~h} \mathrm{~cm}^{-2}$ and a higher current density of $4 \mathrm{~mA} \mathrm{~cm}^{-2}$ were also investigated. Full cells were assembled by pairing $\mathrm{LiFePO}_{4}$ with $\mathrm{Li}$ plated NCNF. The areal loadings of $\mathrm{LiFePO}_{4}$ and $\mathrm{Li}$ metal are about 2.7 and $0.52 \mathrm{mg} \mathrm{cm}^{-2}$ respectively in the cell which contains $40 \mu \mathrm{L}$ electrolyte.

\section{RESULTS AND DISCUSSION}

The SEM images of the PAN-based film and the resulting carbonized NCNF are shown in Fig. 2a, b, showing the fiber morphology in both cases. The NCNF has a smooth surface with a diameter around $250 \mathrm{~nm}$, which is slightly smaller compared to that for the PAN film without carbonization. This intertwined network renders the high structure stability and flexibility (Fig. S1), making it easy to be used as the electrode directly. The density of NCNF is only $0.57 \mathrm{mg} \mathrm{cm}^{-2}$, and the stable structure can effectively buffer the volume changes of Li during the plating/ stripping process. The $\mathrm{N}_{2}$ adsorption/desorption isotherms belong to type I (Fig. 2c) with a SSA of $214 \mathrm{~m}^{2} \mathrm{~g}^{-1}$, which is profit to the uniform $\mathrm{Li}$ deposition. Raman spectrum of the NCNF (Fig. 2d) shows two dominant peaks at $1,342 \mathrm{~cm}^{-1}$ and $1,584 \mathrm{~cm}^{-1}$, which are the characteristic $D$ and $G$ bands of carbon materials, and the intensity ratio of $\mathrm{D}$ band and $\mathrm{G}$ band $\left(I_{\mathrm{D}} / I_{\mathrm{G}}\right)$ is 0.985 , confirming the existence of many defects and edges that are active for the $\mathrm{Li}$ nucleation. The electrical conductivity of NCNF was obtained by using a four-point probe and the value is $3.171 \times 10^{-2} \mathrm{~S} \mathrm{~cm}^{-1}$. The high SSA and electrical conductivity can effectively reduce the local current density, promoting the uniform deposition of NCNF. XPS analyses were performed to further characterize the chemical composition of NCNF. The survey XPS spectrum (Fig. 2e) showed that the NCNF consisted 
of C (85.8 at\%), N (9.5 at\%) and O (4.7 at\%) elements. The fitting result of the $\mathrm{N} 1 \mathrm{~s}$ fine scan spectra can be devoted into three peaks (Fig. 2f), pyridinic nitrogen (pnN, $398.2 \mathrm{eV}, 48.52 \%)$, pyrrolic nitrogen (prN, $400.7 \mathrm{eV}, \quad 45.49 \%)$ and quaternary nitrogen (qN, $402.5 \mathrm{eV}, 5.99 \%)$ respectively. The existence of nitrogencontaining functional groups, especially $\mathrm{pnN}$ and $\mathrm{prN}$, makes the NCNF matrix lithiophilic, guaranteeing the uniform $\mathrm{Li}$ nucleation and further suppressing the $\mathrm{Li}$ dendrite growth. As for the NCNF-1000, the nitrogendoping content is only 2.6 at\% (Fig. S2) since the higher temperature leading to the loss of nitrogen. The $\mathrm{N}$ contents of NCNF and NCNF-1000 measured by the elemental analyzer were $9.3 \mathrm{wt} \%$ and $2.0 \mathrm{wt} \%$ respectively, which are similar to the XPS results. The decrease of nitrogen content in PAN-based fibers during the high temperature is ascribed to the aromatization of PAN. The $\mathrm{C}=\mathrm{N}$ bonding will be broken with the increase of temperature, releasing heteroatoms $(\mathrm{N})[43,44]$. The SSA of NCNF-1000 is $893 \mathrm{~m}^{2} \mathrm{~g}^{-1}$. The NCNF and NCNF-1000 show similar adsorption isotherms which belong to type I (Fig. S3), and the sharp increase of the adsorption volume at the low relative pressure of NCNF-1000 suggests it has much more micropores.

The metallic Li nucleation and growth behaviors on $\mathrm{Cu}$ foil and NCNF were investigated under the current density of $1 \mathrm{~mA} \mathrm{~cm}^{-2}$. Fig. 3a shows the heterogeneous and rough surface of $\mathrm{Cu}$ foil. When $0.5 \mathrm{~mA} \mathrm{~h} \mathrm{~cm}{ }^{-2} \mathrm{Li}$ was deposited (Fig. 3c), the rough surface with some $\mathrm{Li}$ clumps or sheet-like metallic Li was observed, indicating the isolated $\mathrm{Li}$ nucleation sites. When the deposited $\mathrm{Li}$ increased to $1 \mathrm{~mA} \mathrm{~h} \mathrm{~cm}^{-2}$ (Fig. 3e), the Li clumps grew and the branch-like Li dendrite was generated, suggesting the plating of $\mathrm{Li}$ was prone to deposit onto the Li clusters. Fig. $3 b$ shows the morphology of the pristine NCNF, which has smooth surface, 3D intertwined network and plenty of void space. When $0.5 \mathrm{~mA} \mathrm{~h} \mathrm{~cm}^{-2} \mathrm{Li}$ was deposited onto the NCNF (Fig. 3d), a uniform layer of Li was distributed on the surface of the carbon nanofibers. When the deposited Li increased to $1 \mathrm{~mA} \mathrm{~h} \mathrm{~cm}^{-2}$ (Fig. 3f), no recognizable Li dendrite was observed and the following deposited Li was relatively evenly distributed, filling the void space and rendering a dendrite-free morphology. The surface of the Li plated NCNF electrode was smooth and flat even with a high Li loading of $3 \mathrm{~mA} \mathrm{~h} \mathrm{~cm}{ }^{-2}$, while that of the Li plated $\mathrm{Cu}$ electrode was very rough (Fig. S4). From the cross-sectional SEM image of the NCNF (Fig. S5), the deposited Li was accommodated inside the $3 \mathrm{D}$ carbon matrix, which can effectively redeem the volume change during the plating/

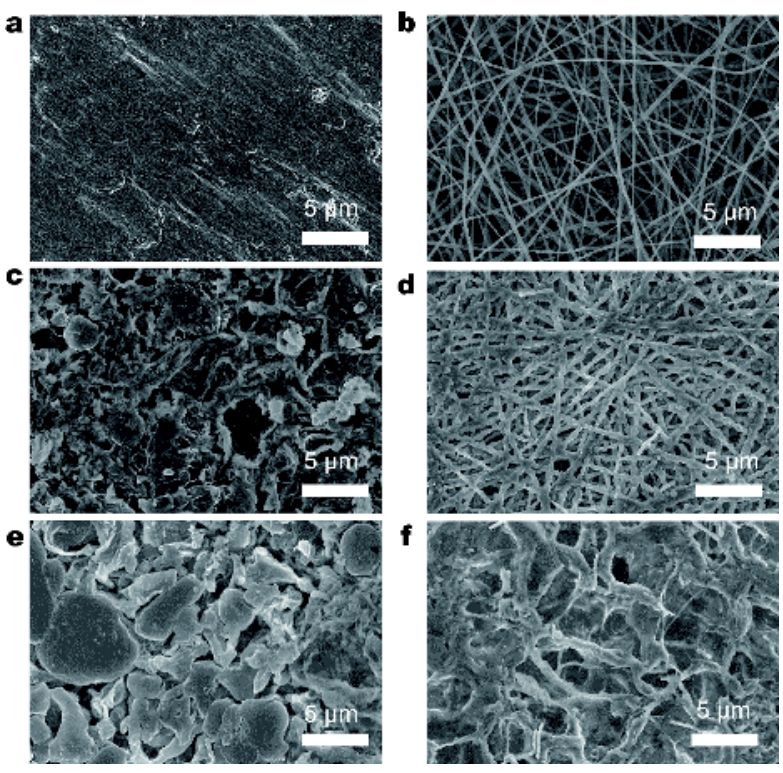

Figure 3 SEM images of the pristine $\mathrm{Cu}$ foil (a), NCNF (b), Cu foil with $0.5 \mathrm{~mA} \mathrm{~h} \mathrm{~cm}{ }^{-2}$ deposited Li (c), NCNF with $0.5 \mathrm{~mA} \mathrm{~h} \mathrm{~cm}{ }^{-2}$ deposited Li (d), $\mathrm{Cu}$ foil with $1 \mathrm{~mA} \mathrm{~h} \mathrm{~cm}{ }^{-2}$ deposited $\mathrm{Li}$ (e) and NCNF with $1 \mathrm{~mA} \mathrm{~h} \mathrm{~cm}^{-2}$ deposited $\mathrm{Li}$ (f).

stripping process. Note that such 3D structure can be well maintained during cycling (Fig. S6), which is crucial for the long cycle stability.

To further prove the roles of nitrogen-containing functional groups for the uniform Li deposition, we investigated $\mathrm{Li}$ plating/stripping behavior on NCNF-1000 which has lower nitrogen-doping content. In spite of the higher conductivity $\left(3.630 \mathrm{~S} \mathrm{~cm}^{-1}\right)$ and larger surface area $\left(893 \mathrm{~m}^{2} \mathrm{~g}^{-1}\right)$, the NCNF-1000 results in uneven Li nucleation and deposition (Fig. S7a-c). The deposited Li metal aggregated on its surface, which easily generated 'dead Li' during the stripping process (Fig. S7d), causing the active material loss and a low coulombic efficiency. This should be ascribed to the following two reasons. First, the higher conductivity of the NCNF-1000 and the higher $\mathrm{Li}^{+}$ion concentration at the electrode surface during plating make the deposition of Li easy to occur at the surface. Second, the less nitrogen-containing functional groups leads to the decrease of the active sites for the $\mathrm{Li}$ nucleation, and as a result, the deposition of $\mathrm{Li}$ becomes uncontrollable in such $3 \mathrm{D}$ matrix.

To evaluate the long cycling performance, half cells were assembled by pairing a Li metal foil with the NCNF or $\mathrm{Cu}$ foil electrode. The cell was firstly cycling at low current density $\left(0.05 \mathrm{~mA} \mathrm{~cm}^{-2}\right)$ between $1 \mathrm{~V}$ and $0.01 \mathrm{~V}$ for 5 cycles to remove impurities and to stabilize the SEI layer, and then $1.0 \mathrm{~mA} \mathrm{~h} \mathrm{~cm}^{-2}$ of Li metal was deposited 

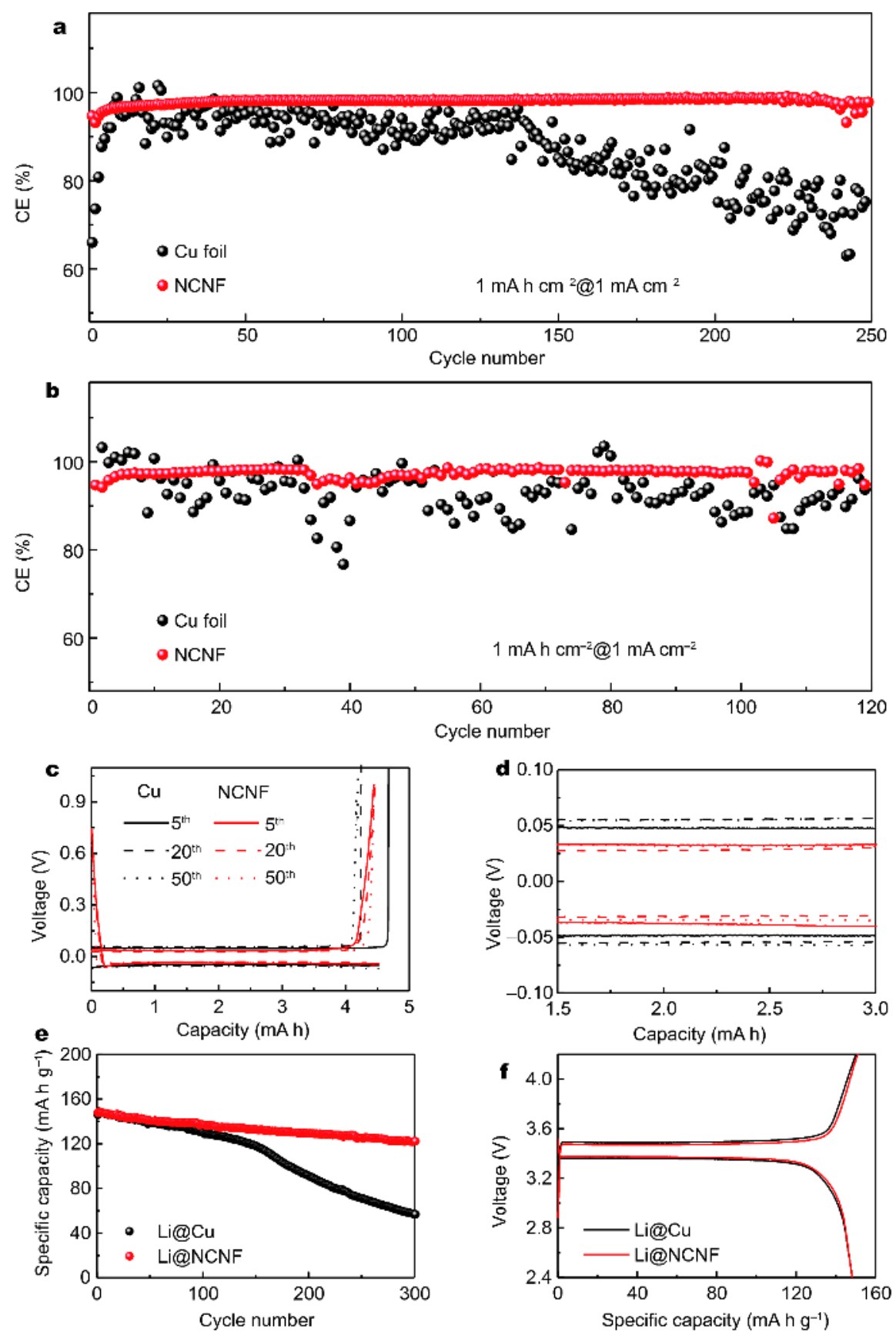

Figure 4 Coulombic efficiency of Li plating/stripping on/from the $\mathrm{Cu}$ and the NCNF current collector for $1 \mathrm{~mA} \mathrm{~h} \mathrm{~cm}^{-2} \mathrm{Li}$ at a current density of $1 \mathrm{~mA} \mathrm{~cm}^{-2}$ (a) and $2 \mathrm{~mA} \mathrm{~h} \mathrm{~cm}^{-2} \mathrm{Li}$ at a current density of $2 \mathrm{~mA} \mathrm{~cm}^{-2}$ (b). Voltage profiles of the $5^{\text {th }}, 20^{\text {th }}$, and $50^{\text {th }}$ cycle of Cu foil and NCNF current collector with a cycling capacity of $4 \mathrm{~mA} \mathrm{~h} \mathrm{~cm}^{-2} \mathrm{Li}$ at $2 \mathrm{~mA} \mathrm{~cm}^{-2}$ (c) and its magnified profiles from $1.5 \mathrm{~mA} \mathrm{~h}$ to $3 \mathrm{~mA} \mathrm{~h}$ (d). Cycling performance of full cells with $\mathrm{Li} @ \mathrm{Cu}$ and Li@NCNF as anode and $\mathrm{LiFePO}_{4}$ at $0.5 \mathrm{C}(\mathrm{e})$ and its charge-discharge profile at $0.5 \mathrm{C}$ (f).

onto the NCNF or $\mathrm{Cu}$ foil current collector at a current density of $1.0 \mathrm{~mA} \mathrm{~cm}^{-2}$, followed by Li metal stripping to $1 \mathrm{~V}$ at the same current density of $1.0 \mathrm{~mA} \mathrm{~cm}^{-2}$. The coulombic efficiencies were calculated as the ratio of the amount of Li metal stripped away to the amount of $\mathrm{Li}$ metal plated in each cycle. The NCNF exhibits high and stable coulombic efficiency over $98 \%$ for 250 cycles while that drops below $90 \%$ after 58 cycles on the Cu surface, which could be attributed to the generation of $\mathrm{Li}$ dendrites (Fig. 4a). When the areal capacity increased to 
$2 \mathrm{~mA} \mathrm{~h} \mathrm{~cm}{ }^{-2}$ and higher current density at $2 \mathrm{~mA} \mathrm{~cm}^{-2}$, coulombic efficiency of the NCNF could also be stabilized over $97 \%$ for 120 cycles, while that on $\mathrm{Cu}$ foil fluctuated severely and soon dropped below $80 \%$ after only $39 \mathrm{cy}$ cles. The coulombic efficiency could be stable above $96 \%$ for 50 cycles on the NCNF surface while that of $\mathrm{Cu}$ oscillated below $80 \%$ with a higher current density of $4 \mathrm{~mA} \mathrm{~cm}^{-2}$ with the areal capacity of $1 \mathrm{~mA} \mathrm{~h} \mathrm{~cm}^{-2}$ (Fig. S8a). Also, with the higher areal capacity of $4 \mathrm{~mA} \mathrm{~h} \mathrm{~cm}^{-2}$ at $2 \mathrm{~mA} \mathrm{~cm}^{-2}$ (Fig. S8b), the coulombic efficiency is stable above $97 \%$ for 80 cycles. Such remarkable cycling performance with high coulombic efficiency is attributed to the nitrogen-containing functional groups, reducing the $\mathrm{Li}$ nucleation overpotential and guiding a uniform Li nucleation and growth. For the low nitrogen-doped NCNF-1000, it exhibited lower coulombic efficiency than NCNF and showed random oscillations after 150 cycles (Fig. S9). We ascribe the inferior stability of NCNF-1000 to its low nitrogen-doping level, which cannot provide sufficient low nucleation sites for $\mathrm{Li}$ nucleation and thus the deposited Li was unevenly distributed on the surface of the current collector, and generating 'dead Li' during stripping process.

Fig. $4 \mathrm{c}$, d show the charge-discharge curves of the NCNF and $\mathrm{Cu}$ foil under plating $4 \mathrm{~mA} \mathrm{~h} \mathrm{~cm}^{-2}$ at $2 \mathrm{~mA} \mathrm{~cm}^{-2}$ after 5, 20 and 50 cycles and their magnified region from 1.5 to $3 \mathrm{~mA} \mathrm{~h} \mathrm{~cm}^{-2}$. The discharging-voltage curves for $\mathrm{Cu}$ foil are shorter than the charging ones after 20 cycles, indicating the irreversible capacity loss and low coulombic efficiency. For the NCNF, there is no notable difference in this respect. The voltage hysteresis for $\mathrm{Cu}$ foil is around $0.11 \mathrm{~V}$, while the NCNF shows reduced hysteresis of only $0.06 \mathrm{~V}$. The smaller value of the flat plating voltage plateau of the NCNF indicates the fast kinetics of $\mathrm{Li}^{+}$migration and superior interface properties due to smaller mass-transfer overpotential. A smaller interface impedance of the NCNF electrode than that of the $\mathrm{Cu}$ foil after first and $20^{\text {th }} \mathrm{Li}$ plating process has been investigated by EIS (Fig. S10). The Li nucleation overpotential (the difference between the sharp tip voltage and the later flat plateau voltage) was investigated to verify the role of the substrate $[35,36,39]$. A voltage dropped to $-0.0642 \mathrm{~V}\left(v s . \mathrm{Li} / \mathrm{Li}^{+}\right)$at the beginning of the $\mathrm{Li}$ nucleation process on $\mathrm{Cu}$ foil, and then stabilized at $-0.0344 \mathrm{~V}$ (Fig. S11), showing the nucleation overpotential was $0.0298 \mathrm{~V}$ for $\mathrm{Cu}$ foil, much greater than the NCNF of $0.0096 \mathrm{~V}$, owing to the lithiophilic nitrogencontaining functional groups in the NCNF. The nucleation overpotential of low nitrogen-doped NCNF-1000 $(0.0165 \mathrm{~V})$ was obviously larger than that of NCNF
$(0.0096 \mathrm{~V})$, suggesting a high nitrogen-doping level reduced the polarization of Li deposition (Fig. S12).

To explore the practical application of the NCNF current collector, full cells were assembled with the $\mathrm{LiFePO}_{4}$ as cathode and NCNF or $\mathrm{Cu}$ foil with $2 \mathrm{~mA} \mathrm{~h} \mathrm{~cm}^{-2}$ deposited Li as anode (Li@NCNF or Li@Cu). The cells were cycled at $0.5 \mathrm{C}$, and improved cycling performance can be observed when NCNF was applied (Fig. 4e). The reversible capacity of the NCNF maintained at $122.4 \mathrm{~mA} \mathrm{~h} \mathrm{~g}^{-1}$ after 300 cycles, corresponding to a capacity retention of $82.4 \%$, while that of $\mathrm{Cu}$ foil was only $38.5 \%$. Meanwhile, the Li@NCNF exhibited lower voltage polarization than that of $\mathrm{Li@Cu}$ indicated the improved kinetics (Fig. 4f).

\section{CONCLUSIONS}

We have fabricated a lightweight free-standing 3D conductive carbon matrix with high nitrogen-doping level as the current collector for Li metal deposition. The densely and uniform-distributed nitrogen-containing functional groups of the NCNF can reduce the Li nucleation overpotential and mass transfer resistance, generating well-distributed $\mathrm{Li}$ seed layer in the initial stage and guiding the even growth of metallic Li during the following plating process. Large SSA and high electrical conductivity can reduce the local current density, inhibiting the generation of $\mathrm{Li}$ dendrites, and more importantly, without compromising the high specific capacity of the Li metal anode due to its lightweight. The 3D intertwined fiber framework can relieve the volume change during Li plating/stripping cycling, stabilizing the electrode structure. As a result, dendrite-free morphology and improved electrochemical performance are achieved. A long plating/stripping cycle with high coulombic efficiency of $98 \%$ can be obtained for 250 cycles and $82.4 \%$ capacity retention after 300 cycles at $0.5 \mathrm{C}$ when pairing with $\mathrm{LiFePO}_{4}$. This work demonstrated the heteroatom doping for the modification of carbon surface to realize the uniform and dendrite-free metal anode deposition, and also showed great potential of light weight NCNF for the use in different metal-based anodes with high energy density.

Received 20 April 2018; accepted 9 May 2018;

published online 4 June 2018

1 Armand M, Tarascon JM. Building better batteries. Nature, 2008, 451: 652-657

2 Goodenough JB. Energy storage materials: A perspective. Energy Storage Mater, 2015, 1: 158-161

3 Zhang C, Yang QH. Packing sulfur into carbon framework for high 
volumetric performance lithium-sulfur batteries. Sci China Mater, 2015, 58: 349-354

4 Palacín MR, de Guibert A. Why do batteries fail? Science, 2016, 351: 1253292-1253292

$5 \mathrm{Xu} \mathrm{K}$. Electrolytes and interphases in Li-ion batteries and beyond. Chem Rev, 2014, 114: 11503-11618

6 Li L, Chen C, Yu A. New electrochemical energy storage systems based on metallic lithium anode-the research status, problems and challenges of lithium-sulfur, lithium-oxygen and all solid state batteries. Sci China Chem, 2017, 60: 1402-1412

7 Bruce PG, Freunberger SA, Hardwick LJ, et al. $\mathrm{Li}-\mathrm{O}_{2}$ and $\mathrm{Li}-\mathrm{S}$ batteries with high energy storage. Nat Mater, 2012, 11: 19-29

8 Choi JW, Aurbach D. Promise and reality of post-lithium-ion batteries with high energy densities. Nat Rev Mater, 2016, 1: 16013

9 Cheng XB, Zhang R, Zhao CZ, et al. Toward safe lithium metal anode in rechargeable batteries: a review. Chem Rev, 2017, 117: 10403-10473

$10 \mathrm{Xu} \mathrm{W}$, Wang J, Ding F, et al. Lithium metal anodes for rechargeable batteries. Energy Environ Sci, 2014, 7: 513-537

11 Lang J, Qi L, Luo Y, et al. High performance lithium metal anode: Progress and prospects. Energy Storage Mater, 2017, 7: 115-129

12 Zhang C, Huang Z, Lv W, et al. Carbon enables the practical use of lithium metal in a battery. Carbon, 2017, 123: 744-755

13 Zhang Y, Qian J, Xu W, et al. Dendrite-free lithium deposition with self-aligned nanorod structure. Nano Lett, 2014, 14: 68896896

14 Heine J, Hilbig P, Qi X, et al. Fluoroethylene carbonate as electrolyte additive in tetraethylene glycol dimethyl ether based electrolytes for application in lithium ion and lithium metal batteries. J Electrochem Soc, 2015, 162: A1094-A1101

15 Zhao $\mathrm{CZ}$, Cheng $\mathrm{XB}$, Zhang $\mathrm{R}$, et al. $\mathrm{Li}_{2} \mathrm{~S}_{5}$-based ternary-salt electrolyte for robust lithium metal anode. Energy Storage Mater, 2016, 3: 77-84

16 Yan $\mathrm{C}$, Cheng XB, Zhao CZ, et al. Lithium metal protection through in-situ formed solid electrolyte interphase in lithiumsulfur batteries: The role of polysulfides on lithium anode. J Power Sources, 2016, 327: 212-220

17 Li W, Yao H, Yan K, et al. The synergetic effect of lithium polysulfide and lithium nitrate to prevent lithium dendrite growth. Nat Commun, 2015, 6: 7436

18 Zhang XQ, Chen X, Cheng XB, et al. Highly stable lithium metal batteries enabled by regulating the solvation of lithium ions in nonaqueous electrolytes. Angew Chem Int Ed, 2018, 57: 5301-5305

19 Li NW, Yin YX, Li JY, et al. Passivation of lithium metal anode via hybrid ionic liquid electrolyte toward stable $\mathrm{Li}$ plating/stripping. Adv Sci, 2017, 4: 1600400

20 Qian J, Xu W, Bhattacharya P, et al. Dendrite-free Li deposition using trace-amounts of water as an electrolyte additive. Nano Energy, 2015, 15: 135-144

21 Chen R, Qu W, Guo X, et al. The pursuit of solid-state electrolytes for lithium batteries: from comprehensive insight to emerging horizons. Mater Horiz, 2016, 3: 487-516

22 Liu X, Ding G, Zhou X, et al. An interpenetrating network poly (diethylene glycol carbonate)-based polymer electrolyte for solid state lithium batteries. J Mater Chem A, 2017, 5: 11124-11130

$23 \mathrm{Lu} \mathrm{Q}, \mathrm{He} \mathrm{YB}, \mathrm{Yu} \mathrm{Q}$, et al. Dendrite-free, high-rate, long-life lithium metal batteries with a 3D cross-linked network polymer electrolyte. Adv Mater, 2017, 29: 1604460

24 Cheng XB, Yan $\mathrm{C}$, Chen $\mathrm{X}$, et al. Implantable solid electrolyte interphase in lithium-metal batteries. Chem, 2017, 2: 258-270
25 Koch SL, Morgan BJ, Passerini S, et al. Density functional theory screening of gas-treatment strategies for stabilization of high energy-density lithium metal anodes. J Power Sources, 2015, 296: 150-161

26 Ma L, Kim MS, Archer LA. Stable artificial solid electrolyte interphases for lithium batteries. Chem Mater, 2017, 29: 4181-4189

27 Wang L, Wang Q, Jia W, et al. Li metal coated with amorphous $\mathrm{Li}_{3} \mathrm{PO}_{4}$ via magnetron sputtering for stable and long-cycle life lithium metal batteries. J Power Sources, 2017, 342: 175-182

28 Zheng G, Lee SW, Liang Z, et al. Interconnected hollow carbon nanospheres for stable lithium metal anodes. Nat Nanotechnol, 2014, 9: 618-623

29 Zhu Y, He X, Mo Y. Strategies based on nitride materials chemistry to stabilize Li metal anode. Adv Sci, 2017, 4: 1600517

30 Li Q, Zhu S, Lu Y. 3D porous $\mathrm{Cu}$ current collector/Li-metal composite anode for stable lithium-metal batteries. Adv Funct Mater, 2017, 27: 1606422

31 Raji ARO, Villegas Salvatierra R, Kim ND, et al. Lithium batteries with nearly maximum metal storage. ACS Nano, 2017, 11: 63626369

32 Wang SH, Yin YX, Zuo TT, et al. Stable Li metal anodes via regulating lithium plating/stripping in vertically aligned microchannels. Adv Mater, 2017, 29: 1703729

33 Yang CP, Yin YX, Zhang SF, et al. Accommodating lithium into 3D current collectors with a submicron skeleton towards long-life lithium metal anodes. Nat Commun, 2015, 6: 8058

34 Yun Q, He YB, Lv W, et al. Chemical dealloying derived 3D porous current collector for Li metal anodes. Adv Mater, 2016, 28: 69326939

35 Zhang C, Lv W, Zhou G, et al. Vertically aligned lithiophilic $\mathrm{CuO}$ nanosheets on a $\mathrm{Cu}$ collector to stabilize lithium deposition for lithium metal batteries. Adv Energy Mater, 2018, 12: 1703404

36 Zhang YJ, Liu SF, Wang XL, et al. Composite Li metal anode with vertical graphene host for high performance Li-S batteries. J Power Sources, 2018, 374: 205-210

37 Zhang R, Li NW, Cheng XB, et al. Advanced micro/nanostructures for lithium metal anodes. Adv Sci, 2017, 4: 1600445

38 Cui J, Zhan TG, Zhang KD, et al. The recent advances in constructing designed electrode in lithium metal batteries. Chin Chem Lett, 2017, 28: 2171-2179

39 Lu LL, Zhang Y, Pan Z, et al. Lithiophilic $\mathrm{Cu}-\mathrm{Ni}$ core-shell nanowire network as a stable host for improving lithium anode performance. Energy Storage Mater, 2017, 9: 31-38

40 Wiegrebe L. An autocorrelation model of bat sonar. Biol Cybern, 2008, 98: 587-595

41 Zhang R, Chen XR, Chen X, et al. Lithiophilic sites in doped graphene guide uniform lithium nucleation for dendrite-free lithium metal anodes. Angew Chem Int Ed, 2017, 56: 7764-7768

42 Liu L, Yin YX, Li JY, et al. Uniform lithium nucleation/growth induced by lightweight nitrogen-doped graphitic carbon foams for high-performance lithium metal anodes. Adv Mater, 2018, 30: 1706216

43 Frank E, Steudle LM, Ingildeev D, et al. Carbon fibers: precursor systems, processing, structure, and properties. Angew Chem Int Ed, 2014, 53: 5262-5298

44 Rahaman MSA, Ismail AF, Mustafa A. A review of heat treatment on polyacrylonitrile fiber. Polym Degrad Stab, 2007, 92: 1421-1432

45 Yan K, Lu Z, Lee HW, et al. Selective deposition and stable encapsulation of lithium through heterogeneous seeded growth. Nat Energy, 2016, 1: 16010 
Acknowledgements The authors acknowledge the financial support from the Guangdong Natural Science Funds for Distinguished Young Scholar (2017B030306006), the National Natural Science Foundation of China (51772164, U1601206 and U1710256), the National Key Basic Research Program of China (2014CB932400), and Shenzhen Technical Plan Project (JCYJ20150529164918734 and JCYJ20170412171359175).

Author contributions $\mathrm{Lv} \mathrm{W}$ and Yang $\mathrm{QH}$ conceived the project. $\mathrm{Wu}$ $\mathrm{H}$ designed and engineered the samples; Zhang $\mathrm{Y}$, Deng $\mathrm{Y}$, Huang $\mathrm{Z}$ and
Zhang $\mathrm{C}$ helped the characterization. Wu $\mathrm{H}$ wrote the paper with support from Yang QH and Lv W. All authors contributed to the general discussion.

Conflict of interest The authors declare no competing interest.

Supplementary information Experimental details and supporting data are available in the online version of the paper.

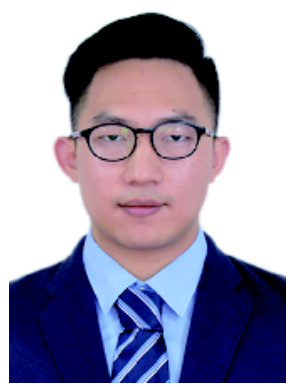

Haoliang Wu received his BSc degree in Applied Chemistry from Tianjin University in 2015 and continued his study as a master candidate under the guidance of Prof. Quan-Hong Yang till now. His research interest includes the design and fabrication of carbon nanostructure and novel electrode materials for energy storage devices.
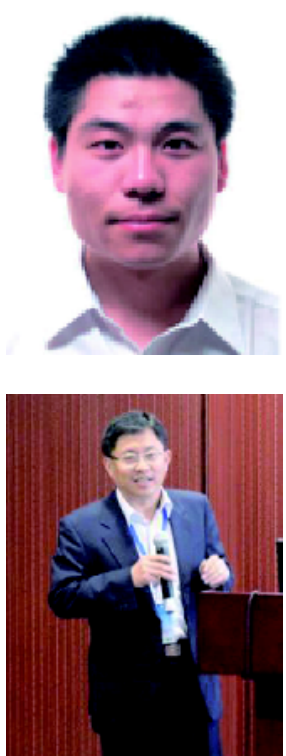

Wei Lv received his PhD from Tianjin University in 2012 under the supervision of Prof. Quan-Hong Yang. He currently works as an Associate Professor in the Graduate School at Shenzhen, Tsinghua University. His research mainly focuses on novel carbon materials, such as graphene and porous carbons, and their applications in electrochemical energy storage.

Quan-Hong Yang was born in 1972, joined Tianjin University as a full professor of nanomaterials in 2006 and became a chair professor in 2016. His research is totally related to novel carbon materials, from porous carbons, tubular carbons to sheet-like graphenes with their applications in energy storage and environmental protection.

\section{用于理金属负极的轻质、高掺氮量碳纳米纤维基三维集流体}

吴浩良 ${ }^{1}$, 张云博 ${ }^{2}$, 邓亚茜 ${ }^{3}$, 黄志佳 ${ }^{2}$, 张琛 $^{3}$, 贺艳兵 ${ }^{3}$, 吕伟 ${ }^{3^{*}}$, 杨全红 $^{1^{*}}$

摘要 锂金属是未来二次电池实现高能量密度化的关键负极材料, 然而, 如何实现锂金属的均匀和无枝晶沉积是目前制约其实际应用的 关键问题. 本论文采用静电纺丝技术及高温碳化方法制备了一种轻质、高掺氮量 $(9.5$ at $\%$ )的三维碳纳米纤维集流体. 该集流体较低的密 度能提升基于整个电池的能量密度, 而且高掺氮量使其具备亲锂的特性, 从而有效降低锂离子在其表面的初始形核过电位, 得到均匀的金 属锂种子层, 实现后续金属锂的均匀沉积. 这种三维结构有效抑制了锂枝晶的产生, 降低了电池的极化, 金属锂沉积/脱除测试中其库伦效 率在循环 250 圈后仍可保持在 $98 \%$ 以上. 将其沉积金属锂后与 $\mathrm{LiFePO}_{4}$ 组装全电池, 电池极化降低, 在循环 300 圈后容量保持率可达 $82.4 \%$, 表 现出很好的应用前景. 